\title{
An acoustic sensor transmitter for in situ assessment of water quality and fish behaviour during chemical treatment of a parasite-infected river system: tag design and practical use
}

Knut Tore Alfredsen ${ }^{1 *} \mathbb{D}$, Henning Andre Urke ${ }^{2}$, Torstein Kristensen ${ }^{3}$, Marte Kvakland ${ }^{4}$, Aage Gronningsater ${ }^{5}$, Anders Gjørwad Hagen ${ }^{4}$ and Jo Arve Alfredsen ${ }^{6}$

\begin{abstract}
Background: Behaviour of potential host fish during chemical treatment against the ectoparasite Gyrodactylus salaris is a vital factor in designing treatment strategies, evaluating risk factors and establishing insights into previously failed treatments. The effectiveness of any chemical treatment may be compromised if fish either are forced to, or seek out actively, areas of the river where the water quality is less affected by the chemicals. The aim of this study was to develop and apply an acoustic fish tag for fish localization with sensors for in situ measurement of water conductivity and temperature to investigate fish behaviour before, during and after an aluminium (Al) treatment. The sensor tag allowed discrimination between water qualities, and thereby quantification of exposure to treatment water.

Findings: Adult Atlantic salmon and anadromous brown trout from river Lærdalselva were tagged with external conductivity transmitters and followed daily by a network of passive receivers and by manual tracking 1 week ahead of treatment, during a 2-week aluminium (Al) treatment period and one week after an Al treatment. The results show no avoidance behaviour related to the Al treatment and most of the fish exhibited a behaviour during the treatment that did not differ significantly from the behaviour observed before or after the treatment. Data collected from the tags showed that the fish experienced increased conductivity during Al administration, suggesting successful exposure to treatment water. The tag gave verifiable environmental information and functioned well in the turbulent and acoustically demanding river environment, albeit with variable detection range.
\end{abstract}

Conclusions: The conductivity and temperature tag provided novel data on fish behaviour and exposure during the Al treatment period. Results show that fish exhibit normal behaviour during this period and no avoidance response can be detected in the collected data.

Keywords: Acoustic telemetry, Conductivity, Salmonids, Aluminium, Water quality, CondTag, Parasite, Gyrodactylus salaris, Atlantic salmon, Anadromous brown trout

*Correspondence: knut.alfredsen@ntnu.no

${ }^{1}$ Department of Civil and Environmental Engineering, Norwegian University of Science and Technology (NTNU), Trondheim, Norway Full list of author information is available at the end of the article

\section{Background}

In Norway, introduction and secondary dispersion of the monogenean parasite Gyrodactylus salaris has caused severe population decline of Atlantic salmon (Salmo salar) in infected rivers $[1,2]$. The discovery of successful

c) The Author(s) 2021. This article is licensed under a Creative Commons Attribution 4.0 International License, which permits use, sharing, adaptation, distribution and reproduction in any medium or format, as long as you give appropriate credit to the original author(s) and the source, provide a link to the Creative Commons licence, and indicate if changes were made. The images or other third party material in this article are included in the article's Creative Commons licence, unless indicated otherwise in a credit line to the material. If material is not included in the article's Creative Commons licence and your intended use is not permitted by statutory regulation or exceeds the permitted use, you will need to obtain permission directly from the copyright holder. To view a copy of this licence, visit http://creativeco mmons.org/licenses/by/4.0/. The Creative Commons Public Domain Dedication waiver (http://creativecommons.org/publicdomain/ zero/1.0/) applies to the data made available in this article, unless otherwise stated in a credit line to the data. 
elimination of G. salaris infections in salmon by exposure to aqueous labile inorganic aluminium $\left(\mathrm{Al}_{\mathrm{i}}\right)$ [3] has led to a scientific [4] and practical [5-7] efforts to develop a full-scale chemical treatment method for parasite elimination while maintaining fish populations in infected river systems. The eliminating effect on G. salaris of labile/cationic $\mathrm{Al}$ in acidified waters was first described by Soleng et al. [3] and the extensive knowledge of biological effects of $\mathrm{Al}$, including dose-response relationships for host species Atlantic salmon and brown trout in the acidification literature [8] defined treatment conditions $(\mathrm{Al}, \mathrm{pH})$. The method involves administering of $\mathrm{Al}$ as aluminium sulphate and acid $\left(\mathrm{H}_{2} \mathrm{SO}_{4}\right)$ for $\mathrm{pH}$ control (target $\mathrm{pH}$ : 5.9-5.7) to obtain a desired concentration of $\mathrm{Al}_{\mathrm{i}}$ between $25-30$ and $\mu \mathrm{g} / \mathrm{l}$. While the causative agent responsible for $G$. salaris removal from the host fish is cationic/labile $\mathrm{Al}$, adding aluminium sulphate and additional sulfuric acid to decrease $\mathrm{pH}$ also results in a marked water conductivity increase in the river during treatment [9]. Thus, the increase in water conductivity caused by the addition of ions and lowering of $\mathrm{pH}$ serves as a practical proxy for measuring dose in situ. At present little is known about the spatio-temporal response pattern of fish to the water quality changes during an $\mathrm{Al}$ treatment period. Both experimental and field studies have demonstrated that Atlantic salmon is able to sense and avoid low $\mathrm{pH}$ [10] and in some cases also elevated concentrations of aluminium [11]. In other cases no avoidance has been observed for aluminium in Atlantic salmon both in the laboratory [12] and for a combined low $\mathrm{pH} /$ increased aluminium in a field study [13].

Fish behaviour during chemical treatment against $G$. salaris is a vital factor in designing treatment strategies, evaluating risk factors and establishing insights into previously failed treatments. The effectiveness of any chemical treatment may be compromised if fish either are forced to, or seek out actively, areas of the river where the water quality is less affected. Areas of brackish water and groundwater runoff are regarded as typical problem areas in this respect. Avoidance and escape reactions from elevated $\mathrm{Al}$ concentrations have been observed previously [14].

The aim of this study was to develop and apply an acoustic fish tag, with sensors capable of simultaneously measuring temperature and conductivity of the surrounding water to investigate to what extent avoidance behaviour occur before, during and after an $\mathrm{Al}$ treatment. The tag was used to track Atlantic salmon (Salmo salar) and anadromous brown trout (Salmo trutta) during the $\mathrm{Al}$ treatment of river Lærdalselva from August to September 2009. During this period the fish are on their spawning run in the river and moves from the estuary to their spawning sites [15]. For salmon and the mature sea trout, both an upriver migration and more stable holding behaviour would be expected [16]. For smaller non-mature sea trout, one could expect both down and upstream migration. The reach of the river studied is the main spawning area of the river, and the fish will mostly spawn in the mainstem. Based on the measured variables, the sensor tag allows for discrimination between water qualities such as ground water, brackish water, chemically treated water and the normal river water. For example, the groundwater runoff to the river Lærdalselva sustains conductivity typically more than ten times that of river water $\left(12-20\right.$ vs $\left.150-350 \mu \mathrm{Scm}^{-1}\right)$. When attached to fish, these transmitters can therefore be used to identify areas in the river and estuary used by fish where the chemical treatment for G. salaris might be suboptimal. Tracking fish before, during and after the treatment also gives indication of the exposure to the chemical reagent in the water and contributes to knowledge on behaviour during the treatment.

The study provides an example and ideas of how experimental objectives may be accommodated within the capabilities and limitations of contemporary digital tag platforms. Detailed field observations showing the dynamics of the fish's exposure to the chemical reagent under the circumstances of a full-scale treatment scenario are given as well as documentation of no avoidance behaviour both during and after treatment.

\section{Methods}

\section{Transmitter design}

An acoustic transmitter tag with a water conductivity and temperature sensor was developed specifically for this study to enable observations of individual behaviour and to quantify the exposure of fish to different water qualities during a chemical treatment. The tag was based on an ultra-low power mixed-signal electronic design similar to the acoustic tag platform described in Føre et al. [17], which allows physical miniaturization while securing long operational life and flexibility with respect to sensor integration, on-board data processing and storage capacity. To sense water conductivity, the tag incorporated a 4-pole gold-plated conductivity cell embedded in one of its end caps (Fig. 1) where the cell constant was dimensioned according to the conductivity range typical for the water in the river and estuary. Conductivity measurements were initiated and supervised by the onboard microcontroller and involved activation of a driver circuit that applied an alternating voltage of constant level to the outer pair of electrodes, while simultaneously sensing the corresponding voltage potential between the inner pair of electrodes and the total electrical current flowing through the water. The microcontroller measured the current and voltage signal for each cycle 


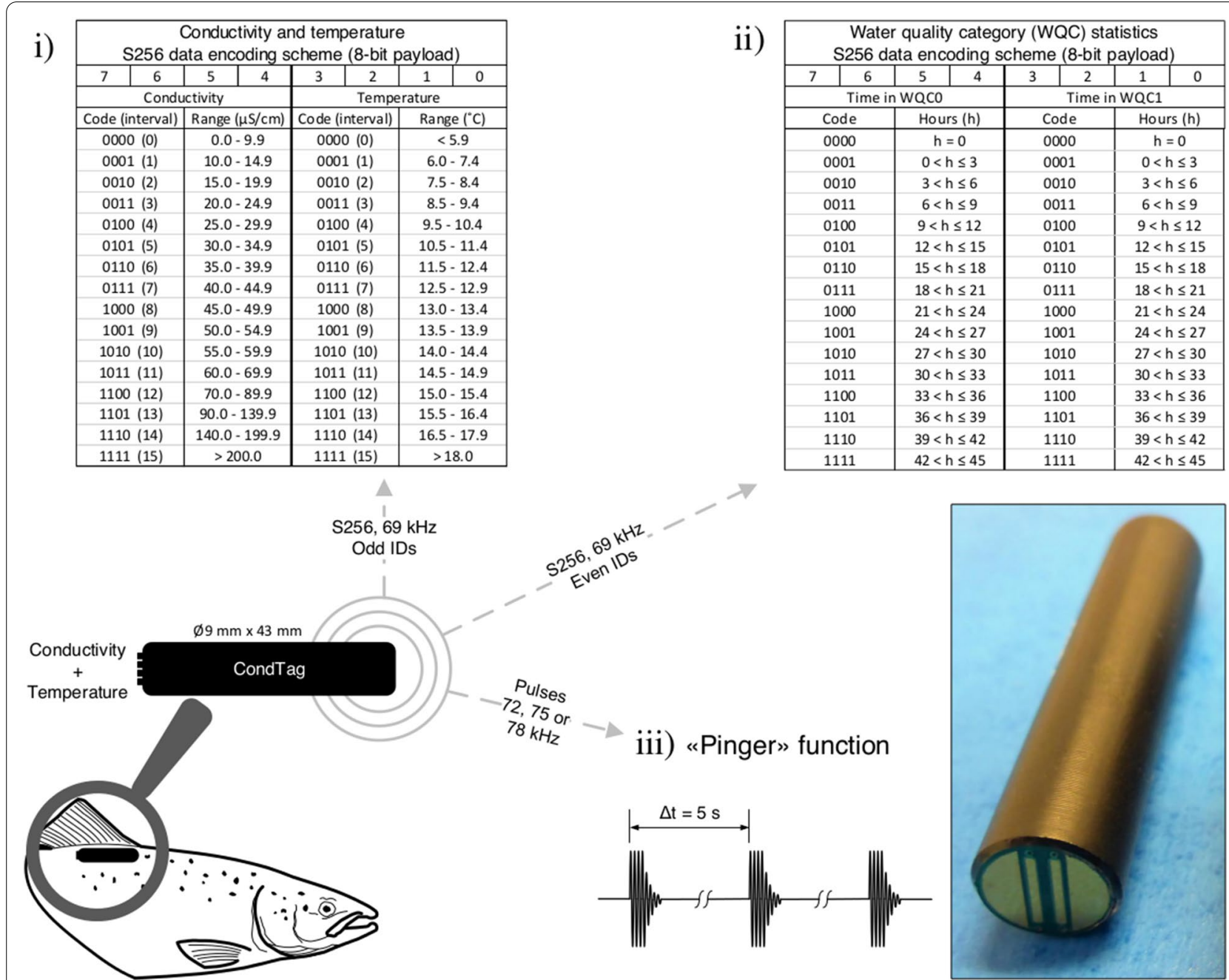

Fig. 1 The conductivity and temperature acoustic transmitter tag (CondTag) with three concurrent transmitter functions. Transmitter function (i) sends S256-encoded messages on odd IDs that contain instantaneous measurements of conductivity and temperature, where the data byte is split in two 4-bit values serving as indices into a look-up table specifying predefined conductivity and temperature intervals. Transmitter function (ii) sends S256-encoded messages on even IDs that contain information reporting how many hours over the last $45 \mathrm{~h}$ the tag has resided in two predefined water quality categories (WQC) defined on the basis of time averages and fluctuations in conductivity measurements. See Table 1 for a description of the WQCs. Transmitter function (iii) runs in parallel with function (i) and (ii) and emits a 20-ms acoustic "pinger" pulse every $5 \mathrm{~s}$ on one of three selectable tracking frequencies $(72,75$ and $78 \mathrm{kHz})$, and is included to enable manual localization and tracking of the fish using manual receivers with a directional hydrophone. The inset image shows the tag with a 4-pole conductivity cell embedded in its endcap. The temperature sensor (not seen) is located on the opposite side of the endcap

by employing a micropower instrumentation amplifier and its integrated AD. Conductivity was calculated as an average over several cycles of the product of the cell constant and the ratio between the measured current and voltage. A calibrated NTC thermistor was embedded in the tag's end cap adjacent to the electrodes and was used to sense ambient water temperature as well as compensating conductivity measurements for temperature dependency. The conductivity and temperature sensors were calibrated with selectable gain and offset settings to accommodate measurement ranges that were considered suitable for the anticipated conditions at the study site. Although the conductivity sensor allowed a maximum measurement range of $0-2530 \mu \mathrm{Scm}^{-1}$, the sensor was set to saturate at $200 \mu \mathrm{Scm}^{-1}$ since the conductivity levels of both normal river water and treatment water were predicted to be very low. This gave a measurement resolution of $0.2 \mu \mathrm{Scm}^{-1}$ and laboratory tests proved that accuracy was better than $1.4 \mu \mathrm{Scm}^{-1}$ for these water types. The temperature sensor had a measurement range of -2.0 to $25.5{ }^{\circ} \mathrm{C}$ with resolution $0.03{ }^{\circ} \mathrm{C}$ and accuracy better than $0.3^{\circ} \mathrm{C}$. 
Both continuous and more sporadic observations of the fish were anticipated in the relatively long and varied river system. For this reason, the tag was designed and programmed as a multi-function transmitter in order to serve three different monitoring objectives simultaneously:

(i) Transmit periodic measurements of instantaneous electrical conductivity and temperature of the tagged fish's ambient water.

(ii) Calculate and transmit statistical information pertaining to the tagged fish's exposure to different water qualities over a defined time history.

(iii) Emit regular and frequent "pings" to permit manual acoustic bearing measurements and localization of the tagged fish using one of three separate tracking frequencies.

In addition to manual tracking receivers, automatic monitoring receivers were used extensively for reception of the telemetry data (Vemco VR100 and VR2W, Halifax, NS, Canada). This implied that transmitter function (i) and (ii) had to be based on an acoustic carrier frequency of $69 \mathrm{kHz}$ and the S256 encoding of acoustic messages [18]. The S256 encoding scheme only permits a 16-bit data payload for each message, which is equally divided between an 8-bit tag ID code and an 8-bit sensor data value. Each transmitter tag was therefore allocated two unique and consecutive ID codes, with odd and even ID codes representing transmitter function (i) and (ii), respectively, with transmission alternating and repeating at random intervals of 40-120 s. On-board compression techniques in terms of look-up tables and calculation of statistical moments were implemented in the tag firmware to convey useful sensor data within the limitation of one byte per transmission. Transmitter function (iii), the acoustic ping, was designed to operate concurrently with function (i) and (ii), but at separate frequencies to avoid acoustic interference with messages transmitted on the $69 \mathrm{kHz}$ channel. The tag was thus programmed to emit short "ping pulses" of $20 \mathrm{~ms}$ duration every $5 \mathrm{~s}$ at either 72,75 of $78 \mathrm{kHz}$ (depending on the tag ID), which thereby permitted concurrent tracking of up to three co-located fish in the same stretch of the river while still being able to receive instantaneous and statistical data on conductivity and temperature.

Transmitter function (i) was implemented to provide instantaneous conductivity and temperature readings from the fish's ambient water as S256-encoded messages. This way data could be received at regular intervals using both automatic monitoring receivers (VR2W) that were permanently deployed in specific pools of the river as well as manual receivers (VR100) that were in ambulatory use during tracking campaigns. Due to the limited one-byte data payload that can be sent during each transmission, conductivity and temperature sensor measurements were compressed into two 4-bit binary codes by a software algorithm that ran locally onboard the tag (see Fig. 1). These codes served as indices into two look-up tables containing predefined conductivity and temperature intervals. The approach employed data binning of each variable into one of 16 different intervals with a nonlinear mapping between bin number and interval size. While having rather low resolution, the mapping technique allowed enhanced resolution in the parts of the sensors' measurement ranges considered likely to prevail during the experiment, at the expense of lower resolution in ranges that were considered less likely to occur. The selection of intervals was done based on a priori knowledge of typical conductivity and temperature ranges of normal river water during the relevant season, as well as values representative of the water quality during $\mathrm{Al}$ treatment, of groundwater effluences, and of the river estuary. Details of the coding scheme of conductivity and temperature intervals are given in Fig. 1.

Transmitter function (ii) was implemented to provide statistical records of the fish's exposure to different water qualities over a specified temporal horizon. With tagged fish moving between locations in the complex and acoustically challenging habitat of the river, it was expected that signals would be beyond detection range of unknown extents of time during the experiment. Still, it was regarded as important to be able to reconstruct historical information concerning the fish's exposure to different water qualities once the fish again could be detected. All remaining data memory on-board the tag was thus allocated to a sliding time window data buffer, and an algorithm was developed to keep record of the fish time of exposure to three different water quality categories (WQC0, WQC1 and WQC2), as defined in Table 1 . The data buffer was configured to cover a $45-\mathrm{h}$ time history and was further divided into 15, 3-h intervals $(15 \times 3 \mathrm{~h}=45 \mathrm{~h})$. For each 3 -h interval, the algorithm calculated and stored the arithmetic mean and the variation, or number of fluctuation events occurring in the conductivity measurements. A fluctuation event was defined to occur when two consecutive conductivity measurements happened to differ by a value greater than a certain threshold value and was included to serve as an indicator of the variability in water quality experienced by the fish. The sensor was sampled every $60 \mathrm{~s}$ giving 180 conductivity measurements per interval. Each interval was then categorized into one of three different WQCs based on these two variables following the criteria shown in Table 1. At the time of acoustic transmission, the information in the buffer was further compressed into two 4-bit codes, each encoding the number of hours the fish 
Table 1 Definition of water quality categories (WQCs)

\begin{tabular}{|c|c|c|c|c|}
\hline $\begin{array}{l}\text { Water quality } \\
\text { category }\end{array}$ & $\begin{array}{l}\text { Range of conductivity } \\
\text { average }\left(\mu \mathrm{Scm}^{-1}\right)\end{array}$ & & $\begin{array}{l}\text { Number of conductivity fluctuation } \\
\text { events }\left(\left|\mathrm{K}_{\mathrm{t}}-\mathrm{K}_{t-1}\right|>5 \mu \mathrm{Scm}^{-1}\right)\end{array}$ & Description \\
\hline WQCO & $0-25$ & And & $=0$ & Normal river water, main stem \\
\hline WQC1 & $26-40$ & And & $<4$ & Stabilized river water during Al treatment \\
\hline \multirow[t]{5}{*}{ WQC2 } & $0-25$ & And & $>0$ & \multirow{5}{*}{$\begin{array}{l}\text { River water with groundwater influence, or other } \\
\text { atypical variations in conductivity, or brackish water } \\
\text { (estuary) }\end{array}$} \\
\hline & & Or & & \\
\hline & $26-40$ & And & $\geq 4$ & \\
\hline & & Or & & \\
\hline & $>40$ & And & Any & \\
\hline
\end{tabular}

WQCs are based on certain combinations of average conductivity and the variation between consecutive conductivity measurements, or fluctuation events, over a 3-h interval containing a total of 180 measurements. A fluctuation event was defined to happen when conductivity changed by more than $5 \mu \mathrm{Scm}{ }^{-1}$ in $60 \mathrm{~s}$

has spent in WQC0 and WQC1 over the last $45 \mathrm{~h}$ (see Fig. 1). Time spent in WQC2 was not transmitted explicitly but could be found implicitly by applying the formula $t_{\mathrm{WQC} 2}=45-\left(t_{\mathrm{WQC} 0}+t_{\mathrm{WQC} 1}\right)$. Details of the tag encoding are shown in Fig. 1.

Following design, implementation and validation of the sensor tag prototype, a batch of 25 tags were manufactured by Thelma Biotel AS (Trondheim, Norway) for use in this study. The electronic tag that was designated as CondTag, had a cylindrical shape with $9 \mathrm{~mm}$ diameter and $43 \mathrm{~mm}$ length, weighed $6.3 \mathrm{~g}$ in air and $4.1 \mathrm{~g}$ in freshwater, had an acoustic source level of $146 \mathrm{~dB} @ 1 \mathrm{~m}$ re. $1 \mu \mathrm{Pa}$, and an estimated battery life of more than 90 days.

\section{Tagging procedure}

Adult Atlantic salmon $(N=6$, mean length $46.9 \mathrm{~cm}, \mathrm{SD}$ $16.1 \mathrm{~cm})$ and anadromous brown trout $(N=16$, mean length $48.4 \mathrm{~cm}, \mathrm{SD} 14.9 \mathrm{~cm}$ ) (Table 2) from river Lærdalselva, Norway (Fig. 2) were caught by angling using sports fishing equipment at several sites along the river. The species are both relevant as primary host (salmon)

Table 2 Length, species and tag-id for the marked fish

\begin{tabular}{|c|c|c|c|c|c|c|c|}
\hline Tag-id instant & Tag-id stat & Species & Length (cm) & Tagged & Tag site & First obs & Last obs \\
\hline 69 & 70 & Anadromous brown trout & 35 & 15.08 & Oye & 16.08 & 17.09 \\
\hline 75 & 76 & Anadromous brown trout & 35 & 07.08 & Rikheim & 19.08 & 22.09 \\
\hline 77 & 78 & Anadromous brown trout & 43 & 06.08 & Rock & 16.08 & 06.09 \\
\hline 81 & 82 & Anadromous brown trout & 33 & 06.08 & David (5.5) & 16.08 & 22.09 \\
\hline 83 & 84 & Anadromous brown trout & 35 & 15.08 & Oye & 16.08 & 09.09 \\
\hline 85 & 86 & Anadromous brown trout & 35 & 07.08 & Gronnebank & 16.08 & 30.08 \\
\hline 91 & 91 & Anadromous brown trout & 43 & 06.08 & Rock & 29.08 & 19.09 \\
\hline 93 & 94 & Anadromous brown trout & 52 & 07.08 & Rikheim & 24.08 & 22.09 \\
\hline 95 & 96 & Anadromous brown trout & 54 & 06.08 & David (5.5) & 29.08 & 29.08 \\
\hline 143 & 144 & Anadromous brown trout & 38 & 15.08 & Oye & 16.08 & 22.09 \\
\hline 145 & 146 & Anadromous brown trout & 31 & 07.08 & Gronnebank & 16.08 & 21.09 \\
\hline 147 & 148 & Anadromous brown trout & 57.5 & 07.08 & $\operatorname{Per}(5.3)$ & 06.09 & 19.09 \\
\hline 151 & 152 & Anadromous brown trout & 48.5 & 06.08 & Rock & 16.08 & 16.08 \\
\hline 155 & 156 & Anadromous brown trout & 41.5 & 06.08 & Per (5.3) & 28.08 & 17.09 \\
\hline 73 & 74 & Atlantic Salmon & 48 & 15.08 & Rock & 25.08 & 06.09 \\
\hline 79 & 80 & Atlantic Salmon & 84 & 06.08 & Robinson (15.7) & 02.09 & 05.09 \\
\hline 87 & 88 & Atlantic Salmon & 55 & 14.08 & Grasmarki & 25.08 & 20.09 \\
\hline 141 & 142 & Atlantic Salmon & 53 & 14.08 & Grasmarki & 16.08 & 15.09 \\
\hline 149 & 150 & Atlantic Salmon & 84 & 07.08 & Sandebank (15) & 24.08 & 22.09 \\
\hline
\end{tabular}

The first tag id refers to the instantaneous measurement (transmitter function i), the second tag id refers to the statistical data (transmitter function ii). The tag date, tag site and first/last observation is also given. For tagging locations not named on Fig. 2, the distance from the estuary is given in kilometres. The fish were not weighed during marking, but using observed weight of similar size fish from the same river we estimated the tag burden of the smallest fish to be $<1.4 \%$. The tag weighs $4.1 \mathrm{~g}$ in water 


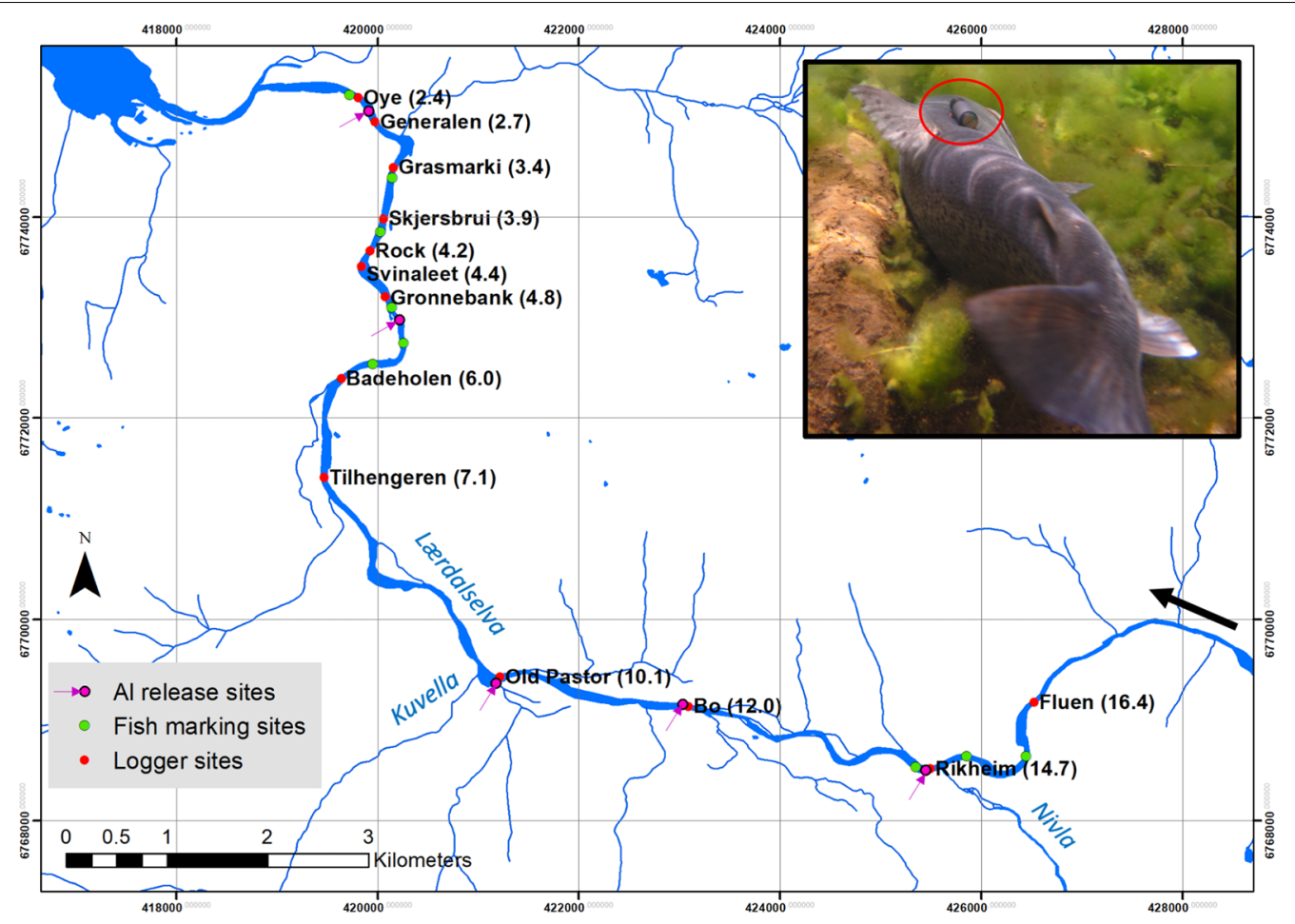

Fig. 2 Map of Lærdal with tracking stations marked along the river reach in red with names. Catch-and-release sites are marked with green and the Al release sites are marked with purple arrows. The numbers in the parentheses is the distance from the estuary. Inset: anadromous brown trout tagged with the conductivity tag

and long-term intermediate host (trout) for the parasite G. salaris [19].

After unhooking, fish were wet netted into a holding tank (volume $500 \mathrm{l}$ ) close to the riverbank. After 20-30 min, fishes were netted directly from the holding tank into a pre-anaesthetic sedation tank containing $0.5 \mathrm{mg} \mathrm{l}^{-1}$ metomidate for a minimum of $2 \mathrm{~min}$. Fishes were then transferred to an anaesthetic bath containing $60 \mathrm{mg} \mathrm{l}^{-1}$ MS 222 (tricaine methanesulfonate) anaesthetic [20]. Cessation of response to peduncle pinching was used as a criterion for surgical anaesthesia. Fishes reached surgical anaesthesia within $4 \mathrm{~min}$ and were then transferred to a tank with river water where the tagging was conducted. During surgery the head, gills, and most of the body of each fish were submerged in water. Total handling time was around $2 \mathrm{~min}$ per fish. Immediately after tagging, the fish were transferred to a recovery tank with river water $(80 \mathrm{l})$ with circulated flow and closely monitored. Fish regained balance ability and showed active swimming behaviour within $0.5-2$ min of recovery. After a recovery period of 5-6 min, the fish were released into the river at the same site as it was angled. During recovery, tag readings were made and compared with data from a control tag permanently installed in the revival tank as well as manual conductivity and temperature measurements (WTW Multiparameter instrument). The tags were fitted with thin surgical steel wire and attached at two points just below the dorsal fin by leading the ends of the wire through the fish using 23 $\mathrm{G}(0.60 \times 25 \mathrm{~mm})$ syringes. The wire ends were secured on the opposite side by crimping on a small copper crimp with a $12-\mathrm{mm}$ soft plastic disk as padding between the crimp and the fish's skin.

\section{Tracking setup}

The fish were followed by a stationary network of automatic listening receivers (VEMCO VR2W, locations shown in Fig. 2 and by daily manual tracking (first by manually deploying a VEMCO VR2W at each release location and later using a portable VEMCO VR100 directional hydrophone during August and September of 2009. Manual tracking was conducted in the river each day between the 14th of August and the 10th of September from 0800 to 2000 by following the same route. Manual tracking was also done on the 16th and 18th of September. This was done by walking upstream along the riverbank and placing both a passive receiver and the hydrophone of manual receiver into the river at different sections of the pools. In pools where fish were detected for more than 2 days, a passive receiver 
was deployed. Once deployed in the river the passive receiver was at the same location during the whole study period. These passive receivers were offloaded daily to check if there had been registered movement of tagged fish during night-time.

The stationary receivers were mounted on the river bottom either using blocks of concrete or specially designed metal stands. Each site except Rikheim had one receiver and range tests were performed to ensure coverage of the entire river width. Lærdalselva is a relatively small river (widths $30-60 \mathrm{~m}$ ) and all sites are easily accessed on the bank. The data from the stationary network and the manual tracking data were combined into a common dataset used in the analysis. For the analysis of the fish behaviour, three phases, before (defined from the 16th of August to the 23rd of August), during (defined from the 26th of August to the 6th of September), and after (defined from the 8th of September to the 15th of September) the Al treatment, were specified to get a consistent comparison of individual fish and to avoid effects of different time of release of the fish after tagging. A gap of 2 days is defined after the start of the treatment on the 24th of August to allow for the treatment to cover the entire river. Similarly, a gap of 1 day is defined between the period of treatment and the start of the after period to allow the treatment chemicals to be transported out of the system. The different phases of the study period are indicated in Fig. 3, which also shows the discharge in the reach during the treatment period. Data were also collected after the 15th of September to check movement and further ensure that fish were alive. For more information on the receiver network used in the experiment in river Lærdalselva, see Urke et al. [20].



Fig. 3 Discharge over the study period measured at the Stuvane gauge (located at the Rikheim tracking station). The coloured panels shows the periods of analysis: a prior to treatment, $\mathbf{b}$ treatment period, $\mathbf{c}$ after treatment
Lærdalselva is a clearwater river and visual counting of salmonid spawners has been conducted from the early 1960 s $[21,22]$. The clear water made it possible to check the status of sensor/fish that had an observed fixed position in the river by snorkelling. One person drifting downstream by snorkelling and one person on the riverbank to register position and observations carried out this procedure. The surveys were conducted both in the upper part (Robinson-Rikheim) and in the lower part (Badehølen-Bruhølen). The diver observed natural behaviour in the fish encountered and fish with tags were seen. No dead fish were observed.

\section{Other data}

Two reference tags were placed at $B \emptyset$ and Øye together with the hydrophones. A continuous measurement of temperature was carried out during the experiment at the same locations by connecting a Vemco Minilog II to the hydrophone stand. Water quality was monitored manually during the treatment period. Discharge is measured at the Stuvane gauge (NVE station 73.2.0) with a time resolution of $30 \mathrm{~min}$. Stuvane is located close to the Rikheim site (Fig. 2).

\section{Aluminium treatment}

Aluminium sulphate was added to all tributaries, as well as at several sites along the main river stem to obtain target concentrations all over the river system. In addition, the main river was acidified using sulphuric acid (30\%) to bring $\mathrm{pH}$ down to effective treatment levels where $\mathrm{Al}$ is labile/cationic. Monitoring was done by using conductivity, $\mathrm{pH}$ and $\mathrm{Al}$ fractionation (Barnes-Driscoll). As the latter being very labour intensive, mainly the two former methods were used for direct control. The $\mathrm{pH}$ measurements were used as a feedback to the dosing stations and conductivity for daily dose control. Conductivity is not strongly related to discharge in this river system and is very low naturally. Monitoring stations upstream of the dosing sites confirmed the increase in conductivity during treatment, and the pre- and post-treatment measurements also confirm this quite consistently.

\section{Statistical analysis}

The relationship between movement and discharge was tested by computing the sum of movements for each halfhour interval that matched the discharge observations and then testing the number of movements against discharge and change in discharge using linear regression. A movement was counted when the fish was found in different locations in two consecutive observations. Conductivity data were checked for normality using qq-plots and histograms, and since the data were skewed, a Box Cox transformation was applied to the data using the package 
EnvStats in $\mathrm{R}$ [23]. The changes in conductivity among the periods before, during and after treatment was then tested by first computing the averages for each fish for each period and then testing this using ANOVA across all periods and then a $t$ test between periods, beforeduring, during-after and before-after. Furthermore, we
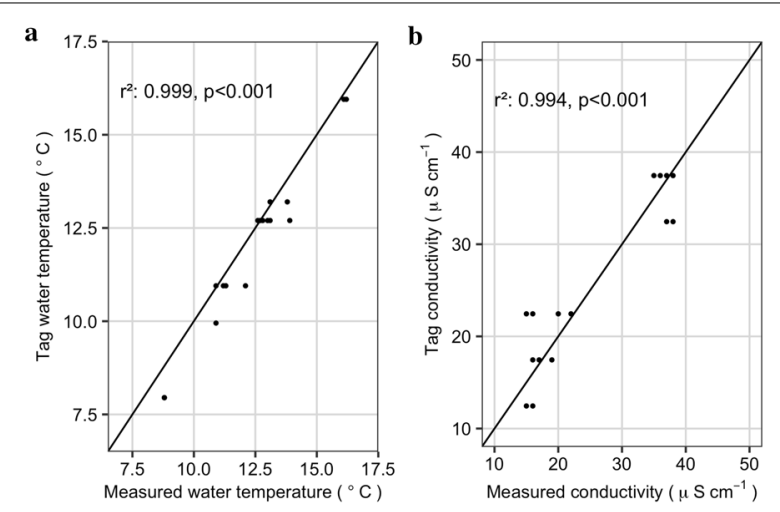

Fig. 4 Comparison conductivity and temperature measured with the tag and a temperature/conductivity meter. Panel a shows water temperature and panel $\mathbf{b}$ shows the conductivity did a similar test on individual fish using ANOVA over all three periods and $t$ tests on pairs of periods for each of the fish that had recordings over different periods. All analysis was done using the R software [24].

\section{Results}

To control the tag reading of temperature and conductivity, measurements were made in the recovery tank after surgery using a calibrated instrument (WTW multiparameter instrument). These were then compared to assess the accuracy of the tags. The recordings confirmed good correspondence between the measurement of temperature and conductivity from the tags and the instrument (Fig. 4, panel a shows temperature, panel b conductivity). This also confirmed that all tags were working at the time of release of the fish.

Of the 22 tagged fish, 19 were detected either by manual tracking or fixed receivers during the study period as indicated in Fig. 5. We find it most likely that the three fish found during the study period were located in areas with difficult acoustic conditions and therefore difficult to detect, but we cannot rule out mortality or tag malfunction. The fish could also have moved out of the study area. Twelve fish were recorded throughout the




experimental period in relation to fixed receiver stations in the river, and the remainder were detected one or several times during the manual tracking campaigns. A total of 32,285 detections were made during the study period, distributed with 4454 before, 14,687 during, and 13,144 in the period after the treatment.

The position and movement of each individual fish are shown in Fig. 5, where the position of the fish is related to its distance from the river estuary. Relatively few movements were observed among the fish during the tracking period. From the data in Fig. 5, it is evident that only three fish out of 19 (16\%, tags 73, 77 and 85) show downstream movements during the period. This occurred during treatment for two of the fish, but both of these fish returned to their original position after some time. The third fish moved $900 \mathrm{~m}$ downstream before the treatment started and stayed there. Five fish showed a distinct upstream movement during the study period (26\%, tags $69,83,141,143$ and 155). All upstream movements took place after the treatment period, and the longest movement was $9.6 \mathrm{kms}$. The remainder of the tagged fish (58\%) held position at one site during the entire period. The largest number of movements was observed in the period after the treatment, but no significant differences exist between the three periods. To check if discharge had an influence on movements, the number of movements was summed for each half-hour (resolution of the discharge times series) and linear regression between instantaneous discharge and the change of discharge were carried out. This shows no pattern connecting observed movement to the observed variability of discharge over the study period, movement vs. instantaneous discharge $\left(r^{2}<0.001, p>0.05\right)$ and movement vs. changes in discharge $\left(r^{2}<0.001, p>0.05\right)$. However, the observed rises and falls reside within normal variations in discharge and could not be considered as floods.

The average experienced conductivity of each fish based on the full set of telemetry data is shown in Fig. 6. There is a significant difference in conductivity experienced by the fish between the treatment periods (ANOVA, $F=7.797, p<0.01$ ). Looking at the different periods, we see a significant increase in conductivity between the period before treatment and the treatment period $(t$ test, $t=-3.6623, p<0.01)$. We also see that the increase in conductivity observed in the telemetry data from the fish tags during the treatment period corresponds with an increase measured in the river for the same period. We do also see a significant reduction in conductivity between the treatment period and the period after $(t$ test, $t=3.0755, p<0.01)$. For the period before and period after treatment there are no significant difference in the conductivity experienced by the fish ( $t$ test, $t=-1.3099$, $p>0.05)$. For the full period, we see that the treatment



Fig. 6 Box plot showing the average conductivity for all fish distributed on the three time periods. The conductivity interval is given in table (i) in Fig. 1. The $p$ values related to the Anova test on differences between the periods are shown in the graph. The thick line represents the median, the box shows the inner quartile range (IQR) and whiskers are at $1.5 *$ IQR

raises the conductivity in the river followed by a reduction back to the level seen in the period before treatment when the treatment is over.

Further, an analysis of each individual fish between periods was carried out; see Fig. 5 for the periods where each tagged fish is observed. For the fish with observations in all three periods, an ANOVA test shows that there is a significant difference between the periods $(p<0.001)$. For fish with observations for the period before and during treatment, with one exception a t-test shows a significant increase in experienced conductivity for each individual fish during the treatment $(p<0.001$ for all fish). The exception is an anadromous brown trout (tag 83) in the lower part of the river that shows only a slightly increase in median conductivity from before treatment to the treatment period. For fish recorded both in the treatment period and the period after treatment, we see a significant reduction in conductivity for all individuals $(p<0.05)$. When we compare the period before treatment to the period after treatment, the picture is mixed. Some fish are seen to return to the same level of conductivity as before the treatment, while for a few individuals we still see a significant difference in experienced conductivity.

As an example of observed conductivity in individual fish, Fig. 7 shows three fish (tags 75, 93 and 149) located at the Rikheim site $14.7 \mathrm{~km}$ from the estuary. These fish were present at this site for long periods during the study, and the results show individual variations that appear to be linked to the specific locations of the fish in the pool, which were determined by taking cross-bearings of the fish's ping pulses (transmitter function iii). The tributary Nivla enters the Rikheim site from the south, and this 


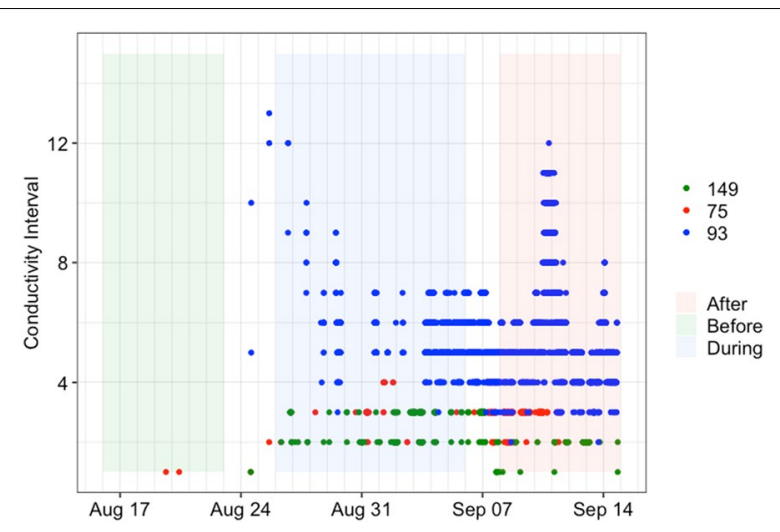

Fig. 7 Measured conductivity intervals for the fish (tag 75 : anadromous brown trout, $35 \mathrm{~cm}$, tag 93: anadromous brown trout $52 \mathrm{~cm}$, tag 149: Atlantic salmon $84 \mathrm{~cm}$ ) located at tracking location Rikheim during the three analysis periods. The boxes show the same distribution as in Fig. 6. Conductivity intervals given in table (i) of Fig. 1

stream discharge water of a natural higher conductivity level than the main river stem. The fish with tag 93 was located at the entrance of the tributary for most of the time and this shows up as a higher level of conductivity measured by the tag when compared to the other two fish which took other positions in the pool. A number of daily measurements at the Nivla outlet during the treatment period gave a median conductivity of $43 \mu \mathrm{Scm}^{-1}$ (interval 7 ), and the median tag value gave $37.5 \mu \mathrm{Scm}^{-1}$ (interval 6). The two other fish had a median value of $22.5 \mu \mathrm{Scm}^{-1}$ (interval 3) during the treatment period.

The statistical function of the tag provided information on the time spent in different water quality categories (WQCs) over a 45-h sliding time window, as outlined in the section on tag design and Fig. 1. Figure 8 shows a situation where a fish (tag 81) intermittently came out of detection range and introduced significant gaps in the data received from this fish, but where the statistical recordings (transmitter function ii, Fig. 1) could be applied to evaluate the fish' continuous exposure to different water qualities irrespective of intermittent loss of contact. Each bar depicts a reception of a single statistical message and shows the fraction of time where the fish was exposed to WQC0 (normal river water-blue colour) or the combination of WQC1 and WQC2 (treatment/ atypical water-red colour) of the preceding 45 -h period. Instantaneous values are indicated as dots on top of the plot. Panel a shows the full dataset, while panel b details a subset of the data where the fish came out of detection range at two occasions and caused significant gaps in the recordings. The first gap lasted $\sim 17 \mathrm{~h}$, from the 1st of September 16:00 to the 2nd of September 09:00. It should be noted that this gap coincided with a distinct rise in river discharge, which could be the reason for loss of reception either by the fish moving out to an area not covered by the receiver or a deterioration of the acoustic channel. When the fish was detected again on the 2nd of September, the first message reveals that the fish had been in stable and low conductivity water (WQC0) over the entire 45-h period preceding the reception of that message, including the $17 \mathrm{~h}$ when reception was lost. For the second gap, the fish was out of detection range for about $20 \mathrm{~h}$, from the $2 \mathrm{nd}$ of September 14:30 to the 3rd of September 10:30. The first message received on the 3rd of September after the gap shows that the fish had sustained $6 \mathrm{~h}$ of exposure to water of elevated and/or fluctuating conductivity levels, and correspondingly a $39 \mathrm{~h}$ of exposure to normal river water over the last $45 \mathrm{~h}$. Increasing exposure to elevated and/or more unstable levels of conductivity can be seen in the following hours, a tendency that continued towards the end of the treatment period and corresponded well with the change in general river water conductivity during the treatment. When the treatment ended, the tag reported an increasing prevalence of WQC0 (normal river water) with some lag due to the 45-h sliding window buffer, as should be expected.

\section{Discussion}

In this paper, we present the design of a multi-function acoustic sensor tag and the results from its practical use on adult Atlantic salmon and anadromous brown trout during a chemical $\mathrm{Al}$ treatment of the river Lærdalselva in Norway. Movements seen in the fish both during and after the treatment can be considered as natural migratory behaviour in Atlantic salmon and brown trout during this period of the year. The effect of the $\mathrm{Al}$ treatment on the fish' ambient water could be observed indirectly as an increased level of conductivity in the measurements received from the tagged fish. This demonstrates the utility of the sensor tag as a tool for in situ evaluation of the treatment process and it further confirms that the fish were exposed to the active reagent during the treatment. The main conclusion from the movement and conductivity data is therefore that the tagged fish showed no obvious signs of flight or avoidance behaviour upon exposure to the chemicals during the treatment. This is an important observation related to the effectiveness of the treatment.

In addition to sending regular instantaneous measurements on water conductivity and temperature, the tag was programmed to carry out an onboard analysis of an internally stored time history of conductivity measurements and report exposure times to different predefined categories of water quality. This function was implemented to prevent discontinuities and gaps in the received datasets due to anticipated limitations in 


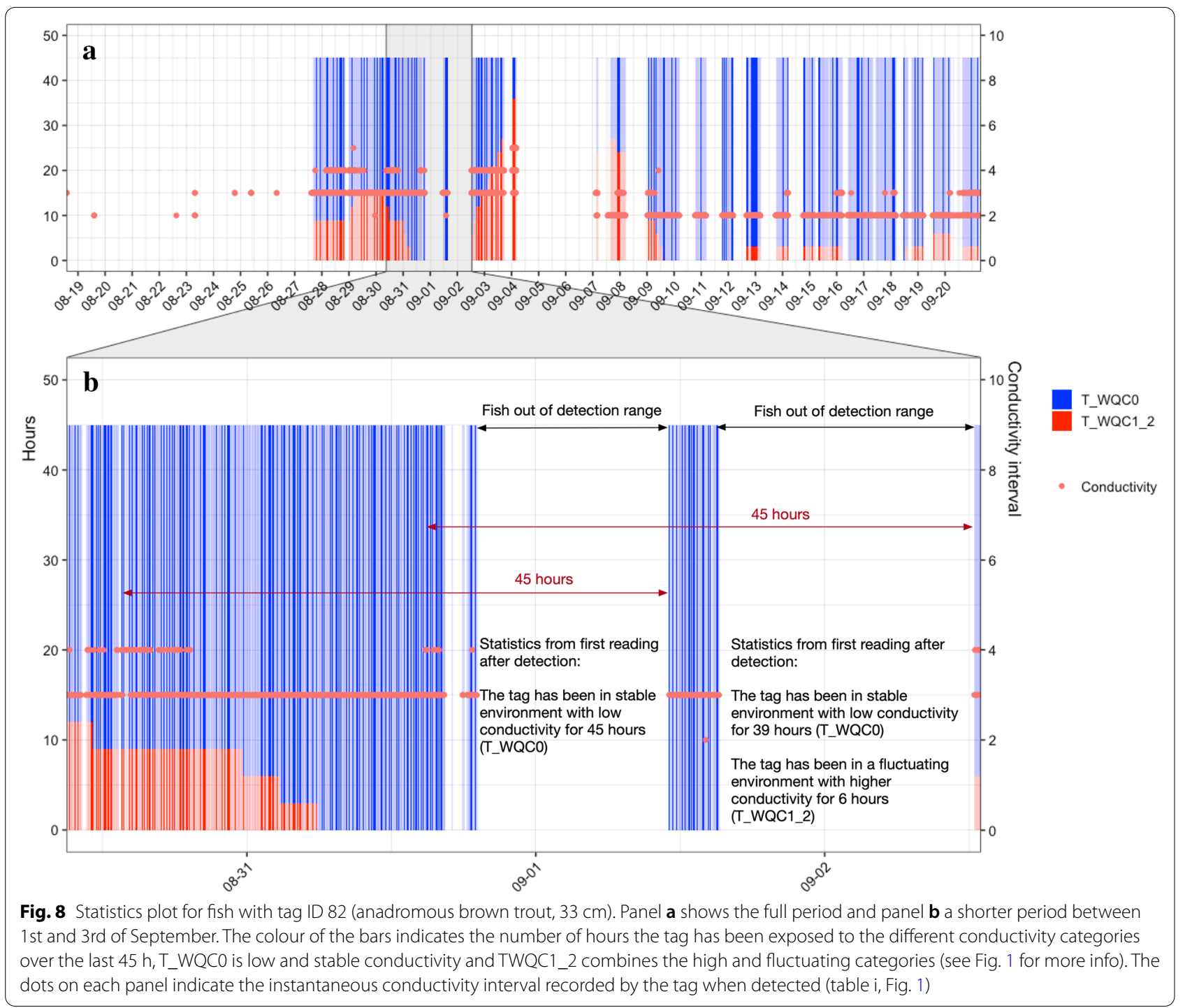

acoustic coverage and signal quality that are caused by the complex environment and turbulent conditions of a river. Given that the tag could be detected again within the time window spanned by its internal data buffer (45 $\mathrm{h}$ in this case), valuable aggregated information on the prevailing water quality conditions when the fish was beyond detection range would be secured. The utility of this function was clearly demonstrated in the case of an anadromous brown trout (tag 81) that was monitored at the site Badeholen throughout most of the study (Figs. 2 and 5), but was intermittently lost towards the end of the treatment period creating gaps in dataset of instantaneous conductivity measurements (Fig. 8). From the received data on exposure time to different water quality categories it was nevertheless possible to conclude that this fish had resided in what was categorized as normal river water (WQC0) during those intervals. However, observations show that the fish was once again exposed to water affected by the reagents at the end of the treatment period. This observation corresponds well with measured conductivity just downstream of the fish location and where an incident in early September when high flow of water with low aluminium concentration from the tributary Kuvella led to a period of low concentration of $\mathrm{Al}_{\mathrm{i}}$ in the main river, which was seen as a reduction in conductivity from $24 \mu \mathrm{Scm}^{-1}$ to $20 \mu \mathrm{Scm}^{-1}$ measured in the river just downstream of the fish location.

From a technical perspective, it should be noted that the statistical function was implemented without including any additional components like memories or computing power to the electronic tag platform. It was exclusively implemented by writing new firmware that exploited already existing hardware resources with only minor costs in battery life due to the extra processing 
requirements. This demonstrates the flexibility and capacity provided by contemporary digital electronic fish tags to carry out on-board processing and analysis of sensor signals prior to transmission over the severely bandwidth-limited acoustic channel, a concept that has been utilized successfully in several subsequent telemetry studies [17, 25-27]. Even if the recorded sensor data must undergo substantial compression and loss of detail before acoustic transmission, the approach features an advantage over archival tags in that no recapture of the tag is needed to recover the data [25].

The tag also incorporated a concurrent acoustic "pinger" function in order to support manual localization and tracking of the fish with directional hydrophones. To avoid interference with the S256-encoded acoustic messages at $69 \mathrm{kHz}$, pings were emitted every $5 \mathrm{~s}$ on a separate frequency. This was shown to work as intended and proved to be a time-saving feature of considerable practical value during manual tracking campaigns where multiple pools and long stretches of the river had to be surveyed. The frequent pings provided rapid confirmation of the presence or absence of fish, which would not be the case if the much less frequent S256 signals (up to $2 \mathrm{~min}$ ) had to be used for this purpose. The pinger function was also instrumental in determining the exact position of the anadromous brown trout (tag 93) at the Rikheim site which reported elevated conductivity levels compared with two other fish residing in the same pool (Fig. 7). Localization of the anadromous brown trout at the outlet of the tributary Nivla, which naturally sustains water of higher conductivity, warranted plausible explanation of the sensor readings and that the observation could not be attributed to the fish taking refuge in an unknown effluent of untreated water (e.g., groundwater), and thereby compromising the efficiency of the $\mathrm{Al}$ treatment.

In general, the acoustic receivers worked well in the stream environment, but turbulence in some areas made manual tracking time-consuming and required accurate positioning of the receiver to detect the transmissions. The simultaneous bankside tracking with the VR-100 and approaching the fish by snorkelling confirmed that fish transmitting a signal from the same location over a long period indeed were alive. A lower detection of fish tagged in the upstream part of the study site (from Rikheim and upstream) was observed during the experiment. Snorkelling confirmed that fish was alive, but heavy riffles and air entrainment made detection more difficult. No dead fish were observed in any of the snorkelling surveys.

One of the main challenges of the tag design presented in this study relates to the selection of appropriate parameters for processing and analyses, as well as achieving sufficient compression of the sensor data, which is required to comply with the severely limited bandwidth of the acoustic telemetry link. The selection of parameters, such as conductivity and temperature bin sizes, averaging intervals and length of the sliding time window, threshold for conductivity fluctuation events, and specification of the different water quality categories (WQCs), all have direct impact on the relevance and quality of the data that may be harvested from the tags. Moreover, the parameters need to be selected prior to the actual study and depend on rather detailed a priori knowledge of the conditions that will prevail during the study. This information may not be fully available at the time of the tag design and programming, particularly if the study is novel and data background is sparse.

Efforts were made in this study to establish the configuration parameters as accurately as possible based on prior analyses of the water chemistry of the river Lærdalselva, both in its normal state and during earlier $\mathrm{Al}$ treatments [9]. However, in hindsight, several changes in the parameter selection could be envisioned in order to improve the performance of the tag. With the conductivity values experienced during this study, it would have been beneficial to select the conductivity intervals with a higher resolution in the lower ranges $\left(<40 \mu \mathrm{S} / \mathrm{cm}^{-1}\right)$ at the expense of lower resolution in the higher ranges. No fish were observed to enter either the estuary or areas with water of high ionic strength such as groundwater effluents during the experiment, and the ability to detect such water qualities could in any case be limited to a couple of wide conductivity intervals above $40 \mu \mathrm{S} / \mathrm{cm}^{-1}$. Moreover, since temperature readings were of limited use in this study, a relocation of one or two bits from the temperature field to the conductivity field of the S256 code would double or quadruple the resolution of the conductivity intervals, respectively. This would undoubtedly make discrimination of normal river water from treatment water significantly clearer and such adjustments in the tag configuration parameters would be straightforward to implement in similar studies in the future.

Acoustic tags have been used in river environments both for Atlantic salmon smolts [20, 28, 29] and adults [30, 31], and provides a well-tested approach for tracking migratory fish in rivers [32]. Davidsen et al. [26] used a variation of the presented conductivity tag to track anadromous brown trout (Salmo trutta) during the CFT Legumin treatment of the river Vefsna to eradicate $G$. salaris. They found no avoidance behaviour and no survival, which indicate a successful rotenone treatment. Similar to the findings of Davidsen et al. [26], there were no avoidance behaviour in the Atlantic salmon and anadromous brown trout tagged in the study presented here, but in contrast no mortality was recorded which is an advantage of the $\mathrm{Al}$ treatment method. In another study, 
Mitamura et al. [27] used a tag based on the design presented here to measure salinity during seaward migration of Atlantic salmon in a fjord in Norway. They utilized both the conventional tracking method and the storage feature of the tag to record the salinity, and found that the statistical data stored on the tag both provided a longer record of data and insight into fish using low salinity areas also in the outer fjord which would be difficult to obtain with a conventional tag and tracking setup.

As mentioned above, the data from the tagging experiment in river Lærdalselva show no obvious response in the fish during the release of $\mathrm{Al}$ and acid to remove $G$. salaris. This is important for the success of the procedure since only a few fish avoiding treatment could ensure the survival of the parasite and thereby reintroduce it to the fish population. A variation in the level of conductivity is observed in individual fish which indicate that they are exposed to different sources of water, which underline the importance of administering the treatment solution to tributaries and other areas where water influx is observed. During the study period all detected fish survived the experiment. This show that the $\mathrm{Al}$ treatment $[5,6]$ for G. salaris can be carried out without killing the host fish populations, which was a key factor in the development of the method. The operation to eradicate the parasite from Lærdal was ultimately considered a success since the control of fish in the river showed no parasite in the following years, and the river was declared free of $G$. salaris in the fall of 2017.

\section{Conclusion}

This paper describes the development of a multi-function acoustic transmitter tag equipped with sensors for in situ measurement of water quality in terms of conductivity and temperature. The tag transmits instantaneous measurements of water quality, while it also features onboard processing of measurement data to obtain statistical information on the fish's exposure to different water qualities over time. The latter function provides the means to evaluate the water quality experienced by the fish when it has been out of detection range. Simultaneously, the tag emits tracking signals (pings) on a separate frequency to facilitate efficient presence detection and fish localization. The tag was applied to provide data on the behaviour and water qualities experienced by Atlantic salmon and anadromous brown trout during an aluminium treatment aimed to eradicate the parasite Gyrodactylus salaris from the river Lærdal in Norway. The measurements obtained from the tagged fish show that the fish were exposed to aluminium during the treatment and that no evidence of avoidance behaviour was detected. The study provides an example of how experimental objectives may be accommodated within the processing capabilities of contemporary digital acoustic tag platforms.

\section{Acknowledgements}

The authors are grateful for the assistance given by T. Grimelid, Ljøsne Hatchery and R.A. Golf, The Norwegian Nature Inspectorate (SNO). The reported work was financed by the Norwegian Environment Agency. The authors thank H.R. Astrup and O. Wendelboe for their hospitality during the field work.

\section{Authors' contributions}

$\mathrm{AaG}$ and JAA designed the acoustic tag based on specifications given by HAU and TK. HAU, TK, AGH and JAA designed the experiment. All authors participated in the field work. MK, KTA, JAA, HAU and TK performed data preparation and analysis. KTA wrote the manuscript with input from all other authors. All authors read and approved the final manuscript.

\section{Funding}

The project was funded by the Norwegian Environmental Agency.

\section{Availability of data and materials}

The datasets used and/or analysed during the current study are available from the corresponding author on reasonable request.

\section{Ethics approval and consent to participate}

Approval for the tagging experiment was granted by the Norwegian Animal Research Authority (ID 1292).

\section{Consent for publication}

Not applicable.

\section{Competing interests}

The authors declare that they have no competing interests.

\section{Author details}

${ }^{1}$ Department of Civil and Environmental Engineering, Norwegian University of Science and Technology (NTNU), Trondheim, Norway. ${ }^{2}$ INAQ AS, Trondheim, Norway. ${ }^{3}$ Faculty of Biosciences and Aquaculture, Nord University, Bodø, Norway. ${ }^{4}$ Norwegian Institute of Water Research, Oslo, Norway. ${ }^{5}$ Thelma Biotel AS, Trondheim, Norway. ${ }^{6}$ Department of Engineering Cybernetics, Norwegian University of Science and Technology (NTNU), Trondheim, Norway.

Received: 20 November 2020 Accepted: 27 January 2021

Published online: 04 February 2021

\section{References}

1. Forseth T, Barlaup BT, Finstad B, Fiske P, Gjøsæter H, Falkegård M, Hindar A, Mo T, Rikhardsen A, Thorstad EB, Vøllestad LA, Wennevik V. The major threats to Atlantic salmon in Norway. ICES J Mar Sci. 2017;74(6):1496-513. https://doi.org/10.1093/icesjms/fsx020.

2. Johnsen $B O$, Jensen A. The Gyrodactylus story in Norway. Aquaculture. 1991;98:289-302.

3. Soleng A, Poleo ABS, Alstad NEW, Bakke TA. Aqueous aluminium eliminates G. salaris (Platyhelminthes, Monogenea) infections in Atlantic salmon. Parasitology. 1999;119:19-25.

4. Poleo ABS, Schjolden J, Hansen H, Bakke TA, Mo TA, Rosseland B, Lydersen $E$. The effect of various metals on G. salaris (Platyhelminthes, Monogenea) infections in Atlantic salmon (Salmo salar). Parasitology. 2003;128:1-9.

5. Hindar A, Garmo Ø, Hagen AG, Hytterød S, Høgberget R, Olstad K (2014) Operational procedures for treatment of the salmon parasite Gyrodactylus salaris by use of the AIS method Norwegian Institute of Water Research ISBN No.: 978-82-577-6434-0.

6. Hindar A, Garmo Ø, Hagen AG, Hytterød S, Høgberget R, Olstad K (2015) Treatment with AIS to eradicate the salmon parasite Gyrodactylus salaris in River Lærdalselva in 2011 and 2012 Norwegian Institute for Water Research ISBN No.: 978-82-577-6436-4.

7. Hytterød S, Pettersen RA, Høgberget R, Lydersen E, Mo TA, Hagen AG (2005) Experimental elimination of Gyrodactylus salaries in River 
Batnfjordselva, Northwestern Norway, with aluminium. North Inst Water Res Rep 5015:30

8. Kroglund F, Rosseland B, Teien H, Salbu B, Kristensen T, Finstad B. Water quality limits for Atlantic salmon (Salmo salar L.) exposed to short term reductions in $\mathrm{pH}$ and increased aluminum simulating episodes. Hydrol Earth Syst Sci. 2008;12:491-507.

9. Hindar A, Garmo Ø, Hagen AG, Hytterød S, Høgberget R, Moen K, Olstad K (2015) Tiltak med AIS for utryddelse av lakseparasitten Gyrodactylus salaris i Lærdalselva i 2011 og 2012 (In Norwegian, summary in English) Norwegian Institute of Water Research ISBN 978-82-577-6436-4 75.

10. Åtland $\AA$, Barlaup BT. Avoidance behaviour of Atlantic salmon (Salmo salar) fry in waters of low pH and elevated aluminium concentration: laboratory experiments. Can J Fish Aquat Sci. 1996;53(8):1827-34.

11. Van Coilie R, Thellen C, Campbell P, Vigneault Y (1983) Effets toxique de l'aluminium chez les salmonidés en relation avec des conditions physicochimiques acides. Can Tech Rep Fish Aquat Sci 1237:88.

12. Åtland $\AA$. Behavioural responses of brown trout, Salmo trutta, juveniles in concentration gradients of $\mathrm{pH}$ and $\mathrm{Al}$-a laboratory study. Environ Biol Fishes. 1998;53:331-45.

13. Lacroix G, Hood D, Smith J. Stability of microhabitat use by brook trout and juvenile Atlantic salmon after stream acidification. Trans Am Fish Soc. 1995;124:588-98.

14. Åtland Å, Barlaup BT. Avoidance of toxic mixing zones by Atlantic salmon (Salmo salar L.) and brown trout (Salmo trutta L.) in the limed River Audna, southern Norway. Environ Pollut. 1995;90(2):203-8.

15. Thorstad EBF, Whoriskey AH, Rikardsen, Aarestrup K (2011) Aquatic Nomads: the life and migration of the Atlantic salmon. Atlantic salmon ecology. In: Aas O, Einum S, Klemetsen A, Skurdal J, Wiley, Chichester, pp. $1-33$.

16. Finstad A, Økland F, Thorstad EB, Heggberget T. Comparing upriver spawning migration of Atlantic salmon Salmo salar and sea trout Salmo trutta. J Fish Biol. 2005;67:919-30. https://doi.org/10.111 1/j.1095-8649.2005.00792.x.

17. Føre M, Alfredsen J, Gronningsater A. Development of two telemetrybased systems for monitoring the feeding behaviour of Atlantic salmon (Salmo salar L.) in aquaculture sea-cages. Comput Electron Agric. 2011;76:240-51.

18. Pincock DG (2008) Understanding the performance of Vemco $69 \mathrm{kHz}$ single frequency acoustic telemetry. Technical White Paper, XDOC- 004372 Version 05, Amirix Systems Inc

19. Paladini G, Hansen H, Williams C, Taylor N, Rubio-Mejia O, Denholm S, Hytterød S, Bron J, Shinn A. Reservoir hosts for Gyrodactylus salaris may play a more significant role in epidemics than previously thought. Parasites Vectors. 2014;7(576):13. https://doi.org/10.1186/s13071-014-0576-5.

20. Urke HA, Kristensen T, Ulvund J, Alfredsen J. Riverine and fjord migration of wild and hatchery reared Atlantic salmon smolts. Fish Manage Ecol. 2013;20:544-52. https://doi.org/10.1111/fme.12042.
21. Finstad A, Einum S, Saettem L, Hellen B. Spatial distribution of Atlantic salmon (Salmo salar) breeders: among- and within-river variation and predicted consequences for offspring habitat availability. Can J Fish Aquat Sci. 2010;67(12):1993-2001. https://doi.org/10.1139/F10-122.

22. Sattem $L$ (2016) Anadromous spawning population in the river Lærdalselva, Lærdal Municipality in Sogn og Fjordane County 2016 (In Norwegian)

23. Millard S. EnvStats: an R package for environmental statistics. New York: Springer; 2013.

24. R Core Team. R: a language and environment for statistical computing. Vienna: Austria, R Foundation for Statistical Computing; 2019.

25. Almeida P, Pereira T, Quintella B, Grønningsæter A, Costa M, J. Jose Lino Costa, . Testing a 3-axis accelerometer acoustic transmitter (AccelTag) on the Lusitanian toadfish. J Exp Mar Biol Ecol. 2013;449:230-8. https://doi. org/10.1016/j.jembe.2013.09.015.

26. Davidsen JG, Thorstad EB, Baktoft H, Aune S, Økland F, Rikardsen AH. Can sea trout Salmo trutta compromise successful eradication of Gyrodactylus salaris by hiding from CFT Legumin (rotenone) treatments? J Fish Biol. 2013:82:1411-8. https://doi.org/10.1111/jfb.12065.

27. Mitamura H, Thorstad EB, Uglem I, Økland F. In situ measurement of salinity during seaward migration of Atlantic salmon post-smolts using acoustic transmitters with data-storage capabilities and conventional acoustic transmitters. Anim Biotelemetry. 2017;5:10.

28. Lothian A, Newton M, Barry J, Walters M, Miller R, Adams C. Migration pathways, speed and mortality of Atlantic salmon (Salmo salar) smolts in a Scottish river and the near-shore coastal marine environment. Ecol Freshw Fish. 2017;27:549-58. https://doi.org/10.1111/eff.12369.

29. Moore A, Privitera MI, Uzyczak J, Beaumont W. The effects of a small hydropower scheme on the migratory behaviour of Atlantic salmon Salmo salar smolts. J Fish Biol. 2018. https://doi.org/10.1111/jfb.13660.

30. Gauld N, Campbell R, Lucas M. Salmon and sea trout spawning migration in the River Tweed: telemetry-derived insights for management. Hydrobiologia. 2016;767(1):111-23. https://doi.org/10.1007/s10750-015-2481-0.

31. Holbrook C, Zydlewski J, Gorsky D, Shepard S, Kinnison M. Movements of prespawn adult Atlantic salmon near hydroelectric dams in the Lower Penobscot River, Maine. North Am J Fish Manag. 2009;29(2):495-505. https://doi.org/10.1577/M08-042.1.

32. Cooke S, Midwood J, Thiem J, Klimley P, Lucas M, Thorstad EB, Eiler J, Holbrook C, Ebner B. Tracking animals in freshwater with electronic tags: past, present and future. Anim Biotelemetry. 2013;1(5):19.

\section{Publisher's Note}

Springer Nature remains neutral with regard to jurisdictional claims in published maps and institutional affiliations.
Ready to submit your research? Choose BMC and benefit from:

- fast, convenient online submission

- thorough peer review by experienced researchers in your field

- rapid publication on acceptance

- support for research data, including large and complex data types

- gold Open Access which fosters wider collaboration and increased citations

- maximum visibility for your research: over $100 \mathrm{M}$ website views per year

At BMC, research is always in progress.

Learn more biomedcentral.com/submissions 